\title{
Rational non-interventional paternalism: why doctors ought to make judgments of what is best for their patients
}

\author{
Julian Savulescu Sub-faculty of Philosophy, University of Oxford
}

\begin{abstract}
This paper argues that doctors ought to make all things considered value judgments about what is best for their patients. It illustrates some of the shortcomings of the model of doctor as 'fact-provider'. The 'fact-provider' model fails to take account of the fact that practising medicine necessarily involves making value judgments; that medical practice is a moral practice and requires that doctors reflect on what ought to be done, and that patients can make choices which fail to express their autonomy and which are based on mistaken judgments of value. If doctors are properly to respect patient autonomy and to function as moral agents, they must make evaluations of what their patients ought to do, all things considered. This paper argues for 'rational, non-interventional paternalism'. This is a practice in which doctors form conceptions of what is best for their patients and argue rationally with them. It differs from old-style paternalism in that it is not committed to doing what is best.
\end{abstract}

It is almost universally accepted that doctors ought to make judgments of what is medically best for their patients. However, the view that doctors ought to make judgments of what is, all things considered, best for their patients has fallen into serious disrepute. It is now widely believed that it is up to patients, not their doctors, to judge what they ought to do, all things considered. I will argue that doctors ought to make value judgments about what is best for their patients, not just in a medical sense, but in an overall sense.

In the bad old days of paternalism, doctors did make judgments about what patients ought to do, all things considered. They also compelled patients to adopt what they judged to be the best course of action. Over the last twenty years, this approach has received much criticism. Liberal societies are founded upon a belief that we each have a fundamental interest in forming and acting on our own

\section{Key words}

Autonomy; paternalism; doctor-patient relationship; value; shared decision-making; rationality. conception of what is good for us, what direction our lives should take, what is, all things considered, best for us. Forming a conception of what is best for oneself and acting on that conception is being an autonomous agent. By taking away from patients the ability to make and act on conceptions of what they judged was best, paternalists frustrated the autonomy of their patients.

There is a second problem with the old approach. Paternalists were making value judgments (often under the guise of what was 'medically or clinically indicated' (1)) which would have been moreo properly made by the patients who were going to be affected by the treatment. Consider one examplece Joe is about to have an operation to remove a tumour from his diaphragm. An anaesthetist visits him preoperatively to discuss his anaesthetic. She then discusses post-operative analgesia. This, she explains, is very important because the major complication after his operation will be the development of lung collapse and pneumonia. If he does not receive adequate analgesia, and is unable to breathe deeply and cough comfortably, this will be much more likely. She informs him that there are two forms of analgesia available after his operation: thoracic epidural analgesia and intravenous narcotic infusion. The analgesic effectiveness of the thoracic epidural is greater. Joe will more easily be able to cough and breathe deeply, so better preventing the development of pneumonia. She explains that the risk of nerve damage from any epidural is around 1/15,000. There is an additional risk with thoracic epidurals in particular: a very small risk of spinal-cord damage from the procedure (damage from the needle) or complications that arise after it (epidural haematoma or abscess). In some of these cases, spinal-cord damage could result in paraplegia. There have only been isolated case reports of these complications so it is not possible to put a figure on how great the risk is but it is certainly very small. Overall, the risk of nerve damage is very small and the risk of developing pneumonia much greater. The anaesthetist explains the significance of developing pneumonia. In some cases, it results in respiratory failure requiring artificial ventilation. Such infections are sometimes very 
difficult to treat and patients stand a reasonable chance of dying if they develop respiratory failure. The overall risk of serious morbidity and mortality is greater if one has the narcotic infusion than if one has the epidural. She recommends having a thoracic epidural. (If she had been a paternalist, she would have simply inserted a thoracic epidural at operation.)

Joe, having understood all this information, chooses to have the narcotic infusion. $\mathrm{He}$ is an active sportsman and the risk of spinal-cord injury is very significant for him. He also claims that he is willing to put up with more pain, and still attempt to cough and breathe deeply, if in this way he will avoid the potential for harm to his spinal cord.

\section{Two reasons}

In this case, which treatment Joe ought to have is not simply determined by facts related to Joe's health (the medical facts). There are two reasons why Joe's doctor ought not make a decision about what is, all things considered, best for Joe. Each has to do with a different sense of 'value'. Firstly, Joe's decision is based on his values, that is, what he is valuing. It is an essential element of self-determination that people construct a notion of what is important in their lives (their values) and act on these. Joe values independence and an active physical life. His choice reflects these values.

Secondly, the question of whether Joe ought to have the thoracic epidural is a value judgment, a judgment of what is of value. Judgments of what is of value, all things considered, are different from judgments of fact. It is a fact, let us assume, that a thoracic epidural is associated with better analgesia and a lower risk of developing pneumonia, but a greater risk of spinal-cord damage, than a narcotic infusion. However, it is not a fact that this makes thoracic epidural overall better for Joe. That is a value judgment. Value judgments must be based on all the relevant facts. These include the medical facts but also facts about the significance of the medical procedures for Joe's own life, and facts about his values. Since no one but Joe knows his plans, his hopes, his aspirations and his values, the argument goes, Joe is better placed than his doctor to evaluate the significance of the various benefits and complications of each treatment. Joe is in a privileged position to judge what is best, all things considered. Joe's doctor, ill-placed to know these other relevant facts, ought to stick to judgments about the medical facts.

For these reasons, medical practice has moved away from the old paternalistic model of 'Doctor knows best' or 'Doctor's orders' to the currently fashionable 'shared decision-making' model.

'Physicians bring their medical training, knowledge, and expertise - including understanding of the available treatment alternatives - to the diagnosis and management of the patients' conditions. Patients bring a knowledge of their own subjective aims and values, through which the risks and benefits of various options can be evaluated. With this approach, selection of the best treatment for a particular patient requires the contributions of both parties' (2).

On one widely held interpretation of this account, doctors bring medical knowledge, medical facts, to the patient who makes a judgment of what ought to be done on the basis of his or her values. Doctors give up making judgments of what is, all things considered, best for the patient and stick to providing medical facts. This approach has found considerable favour in the literature and in practice. Many informed general practitioners and medical students whom I have taught tell me that doctors ought not make tricky value judgments about their patients' lives.

This model of doctor as fact-provider has some serious shortcomings.

Firstly, it is not clear that doctors can avoid making value judgments about what patients ought to do, should do, or what it is best for them to do. Sometimes these value judgments are difficult to spot. Consider the oncologist whose patient has lung cancer. 'Chemotherapy is medically indicated', he says. This appears to be a purely descriptive, factual statement. But it is really also a prescription to have chemotherapy. If we were to ask this oncologist wh chemotherapy was medically indicated, he migh 5 offer this argument: 1 . chemotherapy will prolong your life; 2 . longer life is better than shorter life; 3 . so you ought to have chemotherapy. Premise 2 is clearly a value judgment.

It is difficult to see how doctors, as persons, could avoid making judgments like 2 . The content of these value judgments varies from person to person, but it is difficult to imagine a person with no values. Most people have some norms which they apply to their behaviour. It is also difficult to imagine that these values do not come into play when a doctor is asked to perform a procedure on a patient.

\section{'Framing effect'}

Perhaps doctors cannot avoid making value judgments, but they should keep these to themselves. According to the fact-provider model, doctors should just provide facts such as, 'Chemotherapy will prolong your life'.

However, it is not clear that facts can be communicated free of value. Psychologists have described how the way information is presented can determine the significance of that information for people. This is called the 'framing effect'. When choice is framed in terms of gain, we are risk-averse. When choice is framed in terms of loss, we are risk-taking (3). For example, lung cancer can be treated by surgery or radiotherapy. Surgery is associated with greater immediate mortality ( 10 per cent $\mathrm{v} 0$ per cent mortality), but better long term prospects (66 per 
cent v 78 per cent five-year mortality). The attractiveness of surgery to patients is substantially greater when the choice between surgery and radiotherapy is framed in terms of the probability of living rather than the probability of dying. This effect still occurs whether the evaluator is a physician or someone with statistical knowledge (4).

The manner in which physicians present information is influenced by their values. Surgeons present the probabilities of the outcome of surgery in terms of survival, not death. It is not clear that framing effects can easily be overcome. Even if we present probabilities in terms of both survival and mortality, people are 'loss averse'. They focus myopically on the loss associated with events (5). Subtle nonverbal cues also influence the impact of information. Indeed, information seems ineluctably to bring with it a message. It is not difficult to recognise what someone values, even if they do not tell us. Far better, I think, to bring the practice out into the open, and argue explicitly for what we believe in.

But let's assume that doctors can give up either making value judgments or communicating them. Should they?

Medicine as a practice is founded on commitment to certain values: pain is bad, longer life is usually better than shorter life, and so on. A part of learning to practise medicine is learning to take on these values. These implicit evaluative assumptions rarely surface because they are a matter of consensus. 'Ethical dilemmas' arise when patient values diverge from medical values (6).

Should medicine give up a commitment to certain values? To be sure, we might believe that some of medicine's values are mistaken. Some ought to be changed or refined. But medicine should have a commitment to some values. Otherwise what would direct research effort, provide a standard of care or a framework for the organisation of practice? Mass consumer choice, a thin reed which bends to the prevailing winds, is sometimes irrational and even chaotic, at other times immovably apathetic, and seems ill-suited to provide such direction alone. This may be slightly hyperbolic, but it does seem true that medicine needs a set of values, no doubt shaped by informed public attitude, which guides practice. Those values must be more substantial than a commitment to do what every individual patient desires.

\section{Moral stakes}

The second serious shortcoming of the doctor as fact-provider model is that medicine differs from many other professional practices in that the doctor is often called upon to do very serious things to his patient. In deciding to ablate a patient's bone marrow prior to bone-marrow transplantation, a doctor is going to make his patient very sick. There is unavoidable serious harm associated with medical practice that is far greater than in engineering or tax consultancy. The moral stakes are much higher. Since medical practice involves serious harm to others, as well as benefit, doctors ought to form a judgment of what ought to be done, all things considered. In the extreme case of assisted suicide, a patient asks her doctor to help her die. Should a person do this without making a decision whether it is for the best? Surely not. It is at least generally true that good moral agents reflect upon and form judgments concerning what they ought to do. The same applies to less spectacular, every-day instances of medical practice. Prescribing an antibiotic may cause renal failure. A good doctor must form a judgment about whether prescribing that antibiotic is really justified, even if the patient has an informed desire to have it.

Thirdly, and most importantly, patients can fail to make correct judgments of what is best, just as doctors can. Patients can fail to make choices which best satisfy their own values (7). They can make choices which frustrate rather than express their own autonomy (8). The mere fact that a competent patient makes an informed choice does not imply necessarily that that choice reflects what he values.

Patients can also make incorrect value judgments. They can fail to give sufficient weight to relevant facts, just as the old paternalists did when they concentrated on the medical facts. Consider an example.

Joan is 35 years old and has a one $\mathrm{cm}$ cancer of the? breast without clinical evidence of lymph node metastasis. Her mother and sisters had cancer of the breast. Her surgeon argues, based on her history and the cytology of the tumour, that she has a very high chance of developing a second carcinoma. He recommends a bilateral mastectomy. This, he argues, will give her the best chance of survival. Joan replies that this will be very disfiguring. She would prefer to have a lumpectomy followed by yearly mammography. This, she argues, will give her a better quality of life.

Joan's surgeon inquires further. It turns out that by better quality of life, she means that she will retain her present physical appearance. Her husband would be shocked if she had a bilateral mastectomy, even if she were to have breast implants. ' $\mathrm{He}$ is very attached to my breasts', she says. Her marriage is difficult at present, and she does not believe that it would survive the shock of such operation.

These are of course relevant facts to which the surgeon was not originally privy. Previously, he believed she ought to have a mastectomy. Are these new facts of sufficient importance to cause him to change his judgment? In some cases, they might be. If survival with lumpectomy and mammography was roughly the same as that after mastectomy, then he might change his mind. If Joan's life was really going to be miserable after a mastectomy, and much happier after a lumpectomy, then this would be a good reason not to have the mastectomy. 
However, in some cases, the surgeon might retain his original judgment. He might believe that, if the risk of dying from not having the mastectomy was significant, that it was not worth risking death to conform to her husband's and society's expectations of her physical appearance. Moreover, he might believe that if her relationship would be destroyed by her having a mastectomy, it was not likely to survive or was not worth dying for. He might believe, not necessarily without basis, that Joan will be unhappy in her marriage whether she has a lumpectomy or a mastectomy. He might believe that Joan is mistaken in attaching so much weight to her husband's attachment to her breasts. He might continue to believe that she ought to have the mastectomy, despite the revelation of new facts. Indeed, even in the presence of all relevant facts, if these could be discovered, he might believe that Joan ought to have a mastectomy. Despite having access to the same facts as Joan, such a doctor might continue to differ with her about what is best and he may continue to try to convince her that she is wrong.

Some value judgments are wrong. To claim that one's life is not worth living because one's bunion is painful is mistaken, no matter how well-informed the judgment. To be sure, doctors make wrong judgments of what is best. But so do patients at times.

It is of course easier to turn the decision over to Joan and just provide some medical facts. It is easier to avoid making an all-things-considered value judgment. It is difficult to discuss with a patient why she holds the views she does. It is difficult to provide an argument for why she is wrong which is convincing to her. But such discussion and argument can help patients to make better decisions for themselves. Good advice, which we should expect from our friends and doctors, consists in more than information.

\section{Shared decision-making}

There has been a movement away from paternalism. There are, however, two ways of responding to the problems which have thrown paternalism into disrepute. The first is for doctors to give up the practice of making judgments about what is, all things considered, best for their patients. They should stick to providing medical facts to competent patients who then make choices as to what is best based on their values. This is the model of 'shared decisionmaking'.

The second approach agrees that in the past doctors concentrated too much on medical facts. Other facts are also important in determining what is best. These include facts about the patient, his values, his circumstances and so on. But this approach denies that the patient has sovereign access to the relevant facts, though in many cases she knows them better than anyone else. Doctors can, and ought to, try to discover these other facts and form for themselves an all-things-considered judgment of what is best. Doctors need not give up making value judgments; they can try to make better value judgments. If a doctor's value judgment differs from that of her patient, she ought to engage her patient, find reasons for their differences, and revise her own views. Or, if her view still appears justified, she ought to continue to attempt to convince her patient that she is wrong.

Does attempting to convince a patient that he is wrong in choosing some course threaten his autonomy? It may. One can argue coercively or noncoercively. There are many ways in which a doctor might get a patient to come around to agreeing with him that do not involve rational convergence between the two parties. I am not discussing these ways of arguing. What I am discussing is attempting to convince a patient by rational argument that he is wrong. Far from frustrating a patient's autonomy, this enables a patient to act and choose more autonomously. There are at least three ways in which this is so.

1: To be autonomous, one must be informed. A doctor, in attempting to convince his patient, will appeal to reasons. Some of these reasons will draw attention to relevant facts. He will be asking his patient to reconsider the significance of these fact 8 for her life. Thinking about these facts in a new lighe her choice will become more active, more vivid and so more an expression of her autonomy (8).

2: The second point I cannot argue for in detail here. For a choice to be autonomous, one must be informed. But one must not only be informed of the facts, but also of what is of value. (Or, a relevant fact is what other people have rationally valued or thought to be of value.)

3: As a result of a patient rethinking her choice and giving reasons for that choice in the process of arguing for it, that choice will become a more rational choice and one which she really does value.

So a doctor ought not to be merely a fact-provider but also an argument-provider. In this way, he enables his patient to make a more autonomous choice.

Paternalists went wrong not in forming judgments about what was best for their patients, all things considered. They went wrong in concentrating too much on only medical facts. Moreover, they went wrong in compelling patients to live according to their, the doctors', evaluations of what was best. That often does violate patient autonomy. If Joan continues to want a lumpectomy despite her surgeon's attempts to convince her that she is wrong, he ought not to compel her to have a mastectomy (though in some cases, he might believe that her judgment is so wrong that he cannot provide what she asks and withdraws from the case). We ought not to compel competent people to do what is best, even if what they desire is substantially less than the best. However, allowing competent people to act on 
their judgment of what is best for their own lives does not imply that those judgments are right. Nor does it imply that doctors should not form for themselves judgments about what is best. Nor does it imply that doctors should not try to convince their patients by rational argument that what they are advocating is the best course. Indeed, a doctor ought to form such judgments for his own sake as a moral agent and the patient's sake as an autonomous agent. We can retain the old-style paternalist's commitment to making judgments of what is, all things considered, best for the patient (and improve it) but reject his commitment to compelling the patient to adopt that course. This practice can be called rational, non-interventional paternalism. It is 'rational' because it involves the use of rational argument. It is 'non-interventional' because it forswears doing what is best.

Medicine is entering a new era. Doctors are now required not only to have medical knowledge, but knowledge of ethics, of what constitutes a value judgment, of the fact/value distinction, of how to make value judgments and how to argue rationally about what ought to be done. This requires new skills. It is relatively easy to be a fact-provider (though how to present facts itself presents a problem). It is easy to turn decision-making over to patients and say: 'There are the facts - you decide'. It is difficult to find all the relevant facts, to form evaluative judgments, and critically examine them. It is even more difficult to engage a patient in rational argument and convince him that you are right. If doctors are to avoid the shortcomings of being mere fact-providers, if they are to function properly as moral agents, if they are to promote patient autonomy, they must learn these new skills. They must learn these skills for another reason: gone are the days when they could make uninformed judgments of what was best for their patients and act on these. Gone too are the days when they did not have to provide a justification for the position they were advocating. And that justification goes beyond the fiction of a 'purely medical' justification.

fulian Savulescu, BMedSci, $M B, B S, P h D$, is Sir Robert Menzies Medical Scholar and Visiting Fellow, Sub-faculty of Philosophy, University of Oxford.

\section{References}

(1) Hope T, Sprigings D, Crisp R. Not clinically indicated: patients' interests or resource allocation? British medical journal 1993; 306: 379-381.

(2) Brock D W, Wartman S A. When competent patients make irrational choices. New England journal of medicine 1990; 322: 1595-1599.

(3) Tversky A, Kahneman D. The framing of decisions and the psychology of choice. Science 1981; 211: 453-458.

(4) McNeil B J, Pauker S G, Sox Jr H C, Tversky A. On the elicitation of preferences for alternative therapies. New England journal of medicine 1982; 306: 12591262.

(5) Kahneman D, Varey C. Notes on the psychology of utility. In: Elster J, Roemer J E, eds. Interpersonal comparisons of well-being. Cambridge: Cambridge University Press, 1991: 127-163.

(6) Thanks to one referee for expanding this point.

(7) See reference (3), and also: Kahneman D, Tversky A. Choices, values, and frames. American psychologist 1984; 39: 341-350.

(8) Savulescu J. Rational desires and the limitation of lifesustaining treatment. Bioethics 1994; 8: 191-222. Savulescu J. Good reasons to die [doctoral dissertation]. Monash University, Jun, 1994.

\section{News and notes}

\section{A future of dignity}

A conference entitled A Future of Dignity: Confronting Ethical Dilemmas of the Elderly, will be held from February 15-16, 1996 at the Sheraton Waikiki Hotel, Honolulu, Hawaii.

As well as addressing such topics as mercy killing, rationing, advance directives and futility, the conference also offers workshops for nurses and for those seeking to form ethics committees.

For further information please contact: Georgene Jansen, Department of Medicine, Sullivan IV, Room 470, 2230 Liliha Street, Honolulu, HI 96817, USA. 